\title{
Intra Professional Issues and Violence Against Doctors - Do We Need to Address this Hidden Link and Hidden Curriculum?
}

Ramadas, S.

Violence against doctors is rampant. While lack of communication skills and empathy (Sharma et al., 2019) are considered as the main doctor related factors for violence, intra professional ethical issues have received little attention.

In a teaching hospital, patient care relies on team work and there can be dissonant notes. The residents are often not trained on how to address conflicting issues, with a scientific temper. Power and hierarchy gradients may play a role in clinical decision making. Compromised ethics engulfed in a conspiracy of silence may also loom large in this horizon. The young residents often tow in line. Thus they learn the wrong lessons through the hidden curriculum.

In this process, do faculty with unfavourable power and/or hierarchy gradients get crushed ethically? Is there a growing distortion in the framework of value systems of the doctors? Does this ultimately give distorted messages to a generation of learners, paving way to intergenerational transmission of faulty values? Can this lead to compromised ethics which can indirectly and distally lead to assault towards doctors?

Are the public smelling a rat somewhere and trying to smoke out the rat by burning the house? We have recently witnessed an elderly doctor being assaulted to death in a hospital in the Indian subcontinent (Bureau, 2019). We need to perform intra professional audits, reflect and rectify maladaptive and unethical practices, to ultimately prevent assault towards doctors.

Dr. Smitha Ramadas

Department of Psychiatry, Government Medical College, M.G. Kavu, Thrissur 680596, Kerala, India.

Email:dr.smitharamadas@gmail.com

\section{Solutions}

- An ethical committee in each institution, to monitor clinical work is a need of the hour.

- Bioethics teaching should be inculcated in the teaching curriculum.

- The summative assessment of residents should not be conducted in their parent institutions to ensure objectivity.

- Faculties need to be trained to conduct and evaluate exams objectively.

- Reflective practice with positive reinforcement of ethical clinical practices should be promoted. Faulty role models need to be condemned.

Thus, ethics in medical practice would not die a slow death and doctors would be restored their respectful position in society.

\section{References}

Bureau, T. T. (2019) NRS Medical College Junior Doctors Assaulted. The Telegraph (Online); 12 June, $19 . \quad$. Available at https://www.telegraphindia.com/states/westbengal/nrs-medical-college-junior-doctorsassaulted/cid/1692258. [Accessed 6 October 2019].

Sharma, S. (2019) The deteriorating patientphysician relationship in India: Is it time to look within? Indian Journal of Medical Ethics, 4, 4, pp.330. 